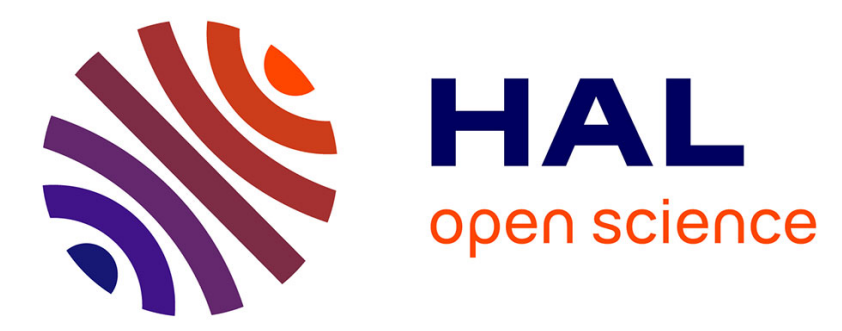

\title{
Farmers follow the herd: a theoretical model on social norms and payments for environmental services
}

\author{
Philippe Le Coent, Raphaële Preget, Sophie S. Thoyer
}

\section{To cite this version:}

Philippe Le Coent, Raphaële Preget, Sophie S. Thoyer. Farmers follow the herd: a theoretical model on social norms and payments for environmental services. Environmental and Resource Economics, inPress, 78 (2), pp.287-306. 10.1007/s10640-020-00532-y . halshs-03060492

\section{HAL Id: halshs-03060492 \\ https://shs.hal.science/halshs-03060492}

Submitted on 2 Feb 2021

HAL is a multi-disciplinary open access archive for the deposit and dissemination of scientific research documents, whether they are published or not. The documents may come from teaching and research institutions in France or abroad, or from public or private research centers.
L'archive ouverte pluridisciplinaire HAL, est destinée au dépôt et à la diffusion de documents scientifiques de niveau recherche, publiés ou non, émanant des établissements d'enseignement et de recherche français ou étrangers, des laboratoires publics ou privés. 


\title{
Farmers follow the herd:
}

\section{a theoretical model on social norms and payments for environmental services}

\section{Philippe Le Coent ${ }^{1}$, Raphaële Préget ${ }^{2}$, Sophie Thoyer ${ }^{2}$}

\begin{abstract}
The economic literature on Payments for Environmental Services (PES) has studied extensively the behavioural factors that prevent farmers from signing PES contracts, even when the payments exceed the expected opportunity costs. This article provides a theoretical model of the role played by the interplay of descriptive and injunctive social norms in farmers' decisions. When they choose to contribute voluntarily to an environmental public good, farmers may be driven by descriptive norms akin to conformity (do as the majority of peers) as well as by injunctive norms (in line with what society expects you to do), which are the equivalent of a social injunction to act in favour of the environment. The interactions between these two social norms can yield multiple equilibria, depending on the relative weight of the descriptive norm (sensitivity to conformism) and of the injunctive norm (sensitivity to moral pressure) in the utility functions of farmers. More generally, our model can explain why social groups are sometimes trapped in low public-goodcontribution equilibria, even when public subsidies to contributors are high. We make policy recommendations to help reach higher contribution equilibria, with a specific focus on the farm policy context.
\end{abstract}

Keywords payments for environmental services, social norms, voluntary contribution to a public good, behaviour, farmers

\footnotetext{
${ }^{1}$ BRGM, Univ. Montpellier, France

${ }^{2}$ INRA, CEE-M, Univ. Montpellier, CNRAS, INRAE, Institut Agro, Bat. 26, 2 Place Pierre Viala, 34000 Montpellier, France
} 
JEL code

Q18, D03 


\section{Introduction}

Society is increasingly vocal about the negative externalities of agricultural activities. Over the past 30 years, agricultural policies have changed to encourage farmers to adopt more environmentally-friendly practices. Incentive policies include agri-environmental policies. They are based on the observation that pro-environmental land management is usually more costly and riskier, and, consequently, based on the assumption that farmers must be financially compensated for their change in practices. Several major agri-environmental policies rely on this approach: Agri-Environmental Measures (AEM) in the European Union since 1992, the Environmental Quality Improvement Program (EQIP) in the United States, and a wide range of Payment for Environmental Services schemes - or equivalently Payments for Ecosystem Services schemes $(\mathrm{PES})^{3}$.

The underlying assumption of proposed PES contracts is that compensating farmers for the additional cost of adopting greener practices is sufficient to induce a change. However, it is observed that some farmers are reluctant to switch to new farming practices even when the payment level is above the additional costs and income foregone (Kuhfuss et al., 2014). Alternatively, there is also empirical evidence that some farmers adopt greener practices even when they are paid a small amount or not at all (Chabe-Ferret and Subervie, 2013). The outcomes of PES schemes are often disappointing, with limited participation rates in some regions, and with low efficiency of public money spending due to windfall effects in others (European Court of Auditors, 2011; OECD 2019).

There is a large body of literature exploring how PES schemes could be redesigned in order to overcome these shortcomings. It has pointed to the fact that the decisions of farmers also depend on perceived transaction costs (Espinosa-Goded et al., 2013) which are rarely taken into consideration in the calculation of the payment, on various institutional constraints

\footnotetext{
${ }^{3}$ We will henceforth use the acronym PES as a generic term for these contracts.
} 
(Mettepenningen et al., 2013), and on contract rules (Mamine et al., 2020). There is also mounting empirical evidence that the motivations of farmers for adopting pro-environmental farming practices are not driven exclusively by economic calculations but respond also to behavioural drivers (see Mills et al., 2018; Dessart et al., 2019; Pannell and Claasen, 2020 for three recent reviews on the subject). Dessart et al. (2019) categorize behavioural drivers as dispositional factors, cognitive factors, and social norms. In this paper, we choose to focus exclusively on the latter although we acknowledge the role played simultaneously by other behavioural factors.

Social norms can be defined as "shared understandings of how individual members should behave in a community" (Chen et al., 2009, p.11812). They describe how individual actions are influenced by the behaviour or opinions of others in the same social group. These actions are either prescribed or proscribed (Elster, 1989), by a kind of informal law system enforced at the level of the group (Cialdini and Trost, 1998). Cialdini et al. (1990) have proposed a division of social norms into descriptive norms and subjective norms. This has subsequently been adopted by many authors, notably in behavioural economics. The descriptive norm is what is perceived as typical or normal, i.e. what most people do. Aronson et al. (2018) describe it as people's perceptions of how the other members of the group behave, "regardless of whether the behaviour is approved or disapproved of others" (p. 270). In this framework, people tend to follow what the majority of their peers in the same social group also do. The injunctive norm refers to what constitutes morally approved and disapproved conduct, i.e. what ought to be done. Injunctive norms influence people because they are the promise of social sanctions or rewards (Cialdini et al., 1990).

The role of social norms has been highlighted for a large range of pro-environmental behaviours adopted by consumers (see Farrow et al., 2017 for a review), for example in the field of energy consumption (Allcott, 2011), water consumption (Ferraro et al., 2011), curbside recycling (Schultz, 1999, Abbot et al., 2013, Czajkowski et al., 2017), and littering (Cialdini et al., 1990). These findings also extend to the adoption of pro-environmental behaviour by producers. In particular, there is a burgeoning literature on how social norms influence farmers in their choice 
of farming practices. The importance of "roadside farming", describing how farmers observe each other's farming practices over the hedge is regularly mentioned in rural sociology studies as a determinant of behaviour (Beedell and Rehman, 2000; Burton, 2004: Burton and Schwarz, 2013). Empirical studies show that a farmer's decision to enrol in a PES scheme is influenced by what other farmers think of the scheme (Defrancesco et al., 2008). Farmers are also more likely to participate if they live close to an area where the participation rate in the PES scheme is already high (Allaire et al., 2009). Other studies based on field experiment approaches (Chen et al., 2009; Kuhfuss et al., 2016, Villamayor-Tomas et al., 2019) or on empirical studies (Lopes et al., 2020, Westerink et al., 2020) reveal that farmers are more likely to join a PES scheme or maintain their pro-environmental practices at the end of the contract, when they are informed that a large number of farmers do likewise in their social group.

These empirical observations have drawn our attention to the importance of understanding in more detail the subtle interplay of the conformism elements and moral elements of social norms (distinguished here under the generic terms "descriptive" and "injunctive" norms), in individual decisions to contribute to the provision of a public good. The purpose of this article is to fill a gap in the literature where very few theoretical models formalize the simultaneous effects of descriptive and injunctive norms. We propose a simple theoretical setting, helping to describe and disentangle how descriptive and injunctive norms can impact decisions to contribute to a public good. It is framed in the context of farm PES schemes because it has been shown that social norms are particularly salient in the case of farming practices.

This article is structured as follows. The first section reviews the existing theoretical models that take into account the role of social norms in pro-social behaviour, with a focus on proenvironmental behaviour. Based on this review, we propose a theoretical model adapted to the specific case of farmers' enrolment into PES programs in section 2. In section 3, we discuss the empirical validity of some of our assumptions. Section 4 presents the policy implications of our model. 


\section{Theoretical modelling of social norms}

Social norms have been modelled in different ways in the literature. In an early model by Lindbeck et al.(1999), a social norm is introduced as a stigma for carrying out an antisocial activity (a negative payoff) that decreases with the number of people infringing it. Lindbeck et al.'s model associates a political (vote) choice on the level of taxes and an economic choice, where individuals choose either to work or to live off social benefits. Receiving public transfers creates "embarrassment" but this is reduced when the proportion of beneficiaries in the society increases. By endogenizing the intensity of the norm felt by people, Lindbeck et al. show that two equilibria can be reached, depending on preferences: a low-tax society supported by a majority of tax-payers (i.e. workers) or a high tax society supported by a majority of transfer recipients.

Rege (2004) formalizes a game of voluntary contribution to a public good in which people have preferences for private consumption, public goods and also social approval. Social approval is a by-product of contribution: non-contributors feel disapproval, whereas contributors feel approval only when they believe they are observed by other contributors. Here again the social norm weighs more heavily in decisions where a larger share of the population adheres to the norm. Rege uses an evolutionary analysis to identify two asymptotically stable states: one in which everybody contributes, and one in which nobody contributes. She shows that a public policy of subsidization of the public good can help to reach the full contribution equilibrium.

These contributions show that social groups can be trapped into a low contribution state and explain why it is sometimes difficult to trigger pro-environmental action at the community level. These results are driven by the way the drivers of social norms are formalized. For example, Nyborg et al. (2006) propose a model of "socially contingent moral motivation", in which individuals feel an obligation to contribute to a public good when they perceive that others also 
take responsibility for providing the public good. In other words, individuals' moral payoff associated with their pro-environmental behaviour increases with the adoption rate of this behaviour in the population. Benabou and Tirole (2012) propose a different approach, based on a social signalling model, bringing together the feeling of distinctness (individual behaviours are substitutes) and conformity (individual behaviours are complements, as usually modelled on social norms).

In these models, the descriptive norm is generally considered only as an increasing function of the adoption rate of a pro-social activity, i.e. support for the adoption of this pro-social activity is weak when few people behave pro-socially and strong when such behaviour becomes more prevalent in the population. This tendency to conform is explained by several factors, notably because it reduces the cognitive burden of deciding how to behave, following the common sense idea that if everyone is doing it, it must be a sensible thing to do (Farrow et al., 2017). In models of pro-social or pro-environmental behaviour, authors indicate that conformity behaviour can be triggered by the indication that responsibility for acting is shared by others, or by feelings of fairness and reciprocity (Brekke and Nyborg, 2010; Nyborg, 2018). However, the existence of conservative forces exhorting people not to undertake pro-social or pro-environmental activities, when few people do so, is generally less considered in the literature. We believe that such forces are at work, as the literature on social stigma shows. Acting differently from the majority can lead to rejection because it threatens the identity of the group (Crocker et al., 1998). This phenomenon is also documented in the case of the farming communities and can explain in some cases the low dissemination of pro-environmental commitments. Indeed, innovative farmers who first adopt more environmentally friendly practices, such as organic farming are sometimes frowned upon and even stigmatized by their peers in the farming community (Burton, 2004; Lähdesmäki et al., 2019). To reflect these findings, we model the descriptive norm as leading to dis-utility when one does not act like the majority. 
Another aspect of the role of social norms, which is not captured well by models, is the way the injunctive norm is formed and subsequently influences behaviour. There is very little information in the literature providing guidance on how general opinion on what should be done is formed and therefore how it could be modelled. We do not address this question in our model but as a result, we make two key assumptions. Firstly, we assume that, when considering the voluntary contribution to a public good, the uniformly shared injunctive norm is always to contribute to the public good regardless of the production level of the public good. Secondly, the intensity of the injunctive norm decreases as the production of the public good increases, due to diminishing marginal utility of the public good. When the public good is scarce, societal pressure (the injunctive norm) to contribute is strong. When the public good becomes abundant, societal pressure for additional contributions remains positive but diminishes.

In the following section, we integrate these two norms in a model representing farmers' participation in a PES scheme.

\section{Modelling the effect of social norms on the adoption of PES}

Section 2.1, presents the general theoretical framework. In the subsequent sections, we study separately the impact of the descriptive norm (2.2) and the impact of the injunctive norm (2.3) before analysing the combined impact of both social norms (2.4).

\subsection{Theoretical framework}

We consider a continuum $[0,1]$ of identical farmers. Each farmer $i \in[0,1]$ has to decide either to participate in a PES scheme $\left(e_{i}=1\right)$ or not $\left(e_{i}=0\right)$. Enrolment in PES corresponds to a contribution of a fixed amount, $e_{i}=1$, to a public good that benefits the whole society. 
Let $x$ denote the share of enrolled farmers in PES, $x \in[0,1]$. Since there is a continuum of farmers, we consider that a farmer $i$ 's enrolment has no effect on the average provision of public good, $\bar{e}=$ $x$. In other words, we consider a context in which the individual farmer does not perceive the benefits of his individual contribution. As in Rege (2004), the strategic aspect of the public good game is therefore not taken into account in this model.

Let $U_{i}$ denote farmer $i$ 's preferences . We use the following specification:

$$
U_{i}=(p-c) e_{i}+f(\bar{e})+\lambda u_{D N}+\sigma u_{I N}
$$

with $c$ the cost to enrol in PES, $p$ the PES payment and $f(\bar{e})$ the farmer's private benefit derived from the average provision of the public good, $\bar{e}$. We assume that $f(0)=0, f^{\prime}>0$ and $f^{\prime \prime}<0$ (primes denote derivatives), i.e. farmers have a decreasing marginal utility for the public good. The social norms are included in the last two components: $u_{D N}$ denotes the utility gains or losses associated with the conformity to the descriptive norm and $u_{I N}$ denotes the utility gains or losses associated with the conformity to the injunctive norm. $\lambda$ and $\sigma$ are scale parameters. $\lambda$ can be interpreted as the weight of the descriptive norm in the utility function of farmers, and $\sigma$ the weight of the injunctive norm. Alternatively, $\lambda$ and $\sigma$ can be interpreted as the salience of the descriptive and injunctive norms respectively. Both scale parameters are assumed to be positive or zero.

The difference in farmer $i$ 's utility between enrolling $\left(U_{i}^{1}\right)$ and not enrolling $\left(U_{i}^{0}\right)$ in PES is given by:

$$
\Delta U=U_{i}^{1}-U_{i}^{0}
$$

Farmers enrol in PES only if this enrolment increases their utility, i.e. only if $\Delta U>0$.

If we do not take social norms into account, i.e. if $\lambda$ and $\sigma$ are set to zero, then $\Delta U=p-c$. In this case, farmers enrol in PES only if the payment $p$ is strictly higher than the cost of enrolment $c$.

Result 1: Without social norms $(\lambda=\sigma=0)$, farmers enrol in PES if and only if $p>c$. 


\subsection{Descriptive norm only: $\lambda>0$ and $\sigma=0$}

We describe the utility gains or losses associated with the conformity to the social descriptive norm $u_{D N}$ with the following specification:

$$
u_{D N}=\left(2 e_{i}-1\right)(2 x-1)
$$

This specification reflects the fact that individuals perceive a utility (disutility) when they conform (do not conform) to the descriptive norm. As shown in Figure 1, if the farmer does not enrol in PES $\left(e_{i}=0\right)$, he gets a positive utility from acting like all other farmers if $x=0$. But his utility decreases as $x$ increases and becomes negative when the majority of farmers enrols in PES, i.e. when $x>\frac{1}{2}$. If the farmer enrols in PES $\left(e_{i}=1\right)$, his utility from not conforming to the descriptive norm is negative when $x=0$, but increases with $x$ and becomes positive as soon as the majority of farmers acts like him, i.e. $x>\frac{1}{2}$.

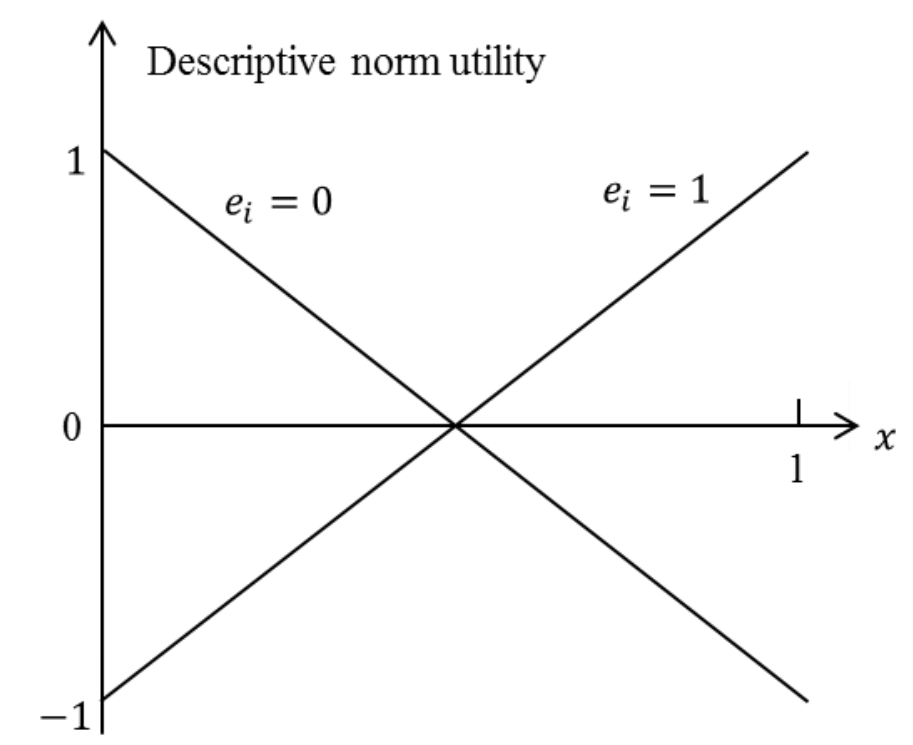

Fig. 1: Utility derived from the level of conformity with the descriptive norm

This specification implies that the descriptive norm is not only exerted by people who adopt a proenvironmental behaviour but also by people who don't. Contrary to Rege (2004) who assumes that 
a non-contributor only feels disapproval, this novel approach intends to reflect the observed resistance of farmers to participate in pro-environmental policies when most farmers don't.

With this descriptive norm specification, and without taking into account the injunctive norm $(\sigma=$ 0 ), farmer $i$ 's utility is:

$$
\begin{gathered}
U_{i}=(p-c) e_{i}+f(\bar{e})+\lambda\left(2 e_{i}-1\right)(2 x-1) \\
\Delta U=p-c+2 \lambda(2 x-1)
\end{gathered}
$$

Let $x^{\prime}$ be defined by $\Delta U=0$, in that case $x^{\prime}=\frac{1}{2}-\frac{p-c}{4 \lambda}$.

\section{Result 2:}

- The game has a Nash equilibrium in which every farmer enrols in PES if and only if $p>$ $c-2 \lambda$.

- The game has a Nash equilibrium in which no farmer enrols in PES if and only if $p \leq c+$ $2 \lambda$.

- If $c-2 \lambda<p \leq c+2 \lambda$ both polar Nash equilibria exist and if $x$ ' lies strictly between 0 and 1 (i.e. $c-2 \lambda<p<c+2 \lambda$ ), there is an additional interior Nash equilibrium in which a share $\left.x^{\prime} \in\right] 0,1[$ of farmers enrol in PES.

Proof: $\Delta U=0$ if and only if $x=x^{\prime}$. Note that $\Delta U$ is an increasing function of $x$. Thus $\Delta U>0$ if and only if $x>x^{\prime}$ and $\Delta U \leq 0$ if and only if $x \leq x^{\prime}$.

Furthermore, note that a Nash equilibrium in which all the farmers enrol exists only if $x^{\prime}<1$ so if and only if $p>c-2 \lambda$. Assuming that all other farmers enrol, then $x=1$, farmer $i$ choosing $e_{i}=1$ will not deviate unilaterally from his choice because $\Delta U>0$. Thus, $e_{i}=1$ for all $i$ is a Nash equilibrium $(e=1)$ if and only if $p>c-2 \lambda$. 
In the same way, note that a Nash equilibrium in which no farmer enrols exists only if $x^{\prime} \geq 0$, so if and only if $p \leq c+2 \lambda$. Assume no farmer enrols, then $x=0$, farmer $i$ choosing $e_{i}=0$ will not deviate unilaterally because $\Delta U \leq 0$. Thus $e_{i}=0$ for all $i$ is a Nash equilibrium $(e=0)$ if and only if $p \leq c+2 \lambda$.

$e_{i}=1$ for a share $x^{\prime}$ of farmers enrolling in PES is also a Nash equilibrium $\left(e=x^{\prime}\right)$ if and only if $c-2 \lambda<p<c+2 \lambda$.

Figure 2 presents the conditions on $p$ for the existence of each Nash Equilibrium.

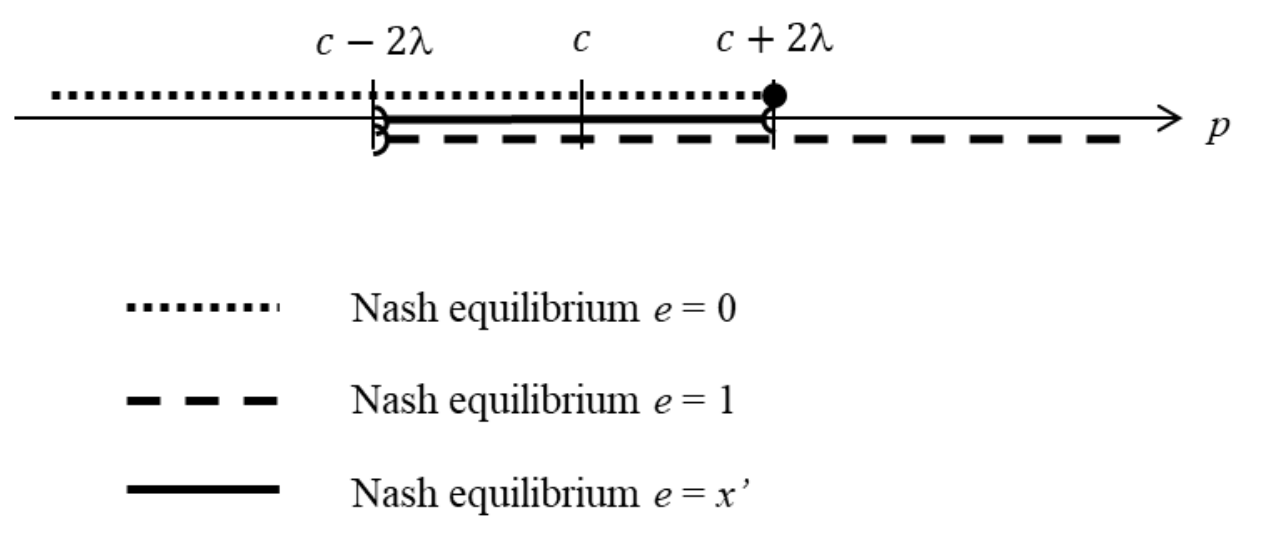

Fig. 2: Nash equilibria with the descriptive norm in relation with the value of $p$

Corollary: $p>c$ is no longer a sufficient condition for farmer $i$ to enrol in PES (when enrolment rate is low), nor $p \leq c$ a sufficient condition for farmer $i$ not to enrol in PES (when enrolment rate is high). Indeed, when enrolment rate is low, the descriptive norm has a negative impact on additional enrolment and can maintain a low enrolment rate even when the monetary compensation is higher than the cost. Conversely, if the enrolment rate is high, the descriptive norm has a positive impact on enrolment and can lead farmers to enrol even if the compensation is lower than the cost. $p>c+2 \lambda$ is a necessary and sufficient condition to have a single Nash equilibrium in which all farmers enrol in PES. 
$p \leq c-2 \lambda$ is a necessary and sufficient condition to have a single Nash equilibrium in which no farmer enrols in PES.

Result 2 implies that when we include descriptive norms in the model, we obtain a coordination game if $c-2 \lambda<p \leq c+2 \lambda$. In this case, the game has three Nash equilibria; one in which every farmer enrols in PES $(e=1)$, one in which no farmer enrols $(e=0)$ and one in which a share $x^{\prime}$ enrol in PES $\left(e=x^{\prime}\right){ }^{4}$

Although our model is static, evolutionary game theory allows us to identify the stable equilibria of our model. See SI (Appendix A) for details and for a formal proof of what we set out below. When the descriptive norm alone is taken into account, our game has only two asymptotically stable states: the two corner Nash equilibria: $e=0$ and $e=1$. This is clearly shown in Figure 3 . Indeed, the interior Nash equilibrium $\left(e=x^{\prime}\right)$ is not an asymptotically stable state because if $x$ is just lower than $x^{\prime}$, then $\Delta U<0$ and all the farmers prefer not to enrol, which gives rise to the polar equilibrium $e=0$. Conversely, if $x$ is just above $x^{\prime}$, then $\Delta U>0$ and all the farmers want to enrol, which leads to the other polar equilibrium $e=1$. Therefore, the two corner equilibria $e=0$ and $e=1$ are stable equilibria, whereas the interior equilibrium $e=x^{\prime}$ is not a stable equilibrium.

\footnotetext{
${ }^{4}$ When $p=c+2 \lambda, x^{\prime}=0$ so the Nash equilibrium $e=x^{\prime}$ is actually the polar Nash equilibrium $e=0$. Thus we have only two Nash equilibria in that case.
} 


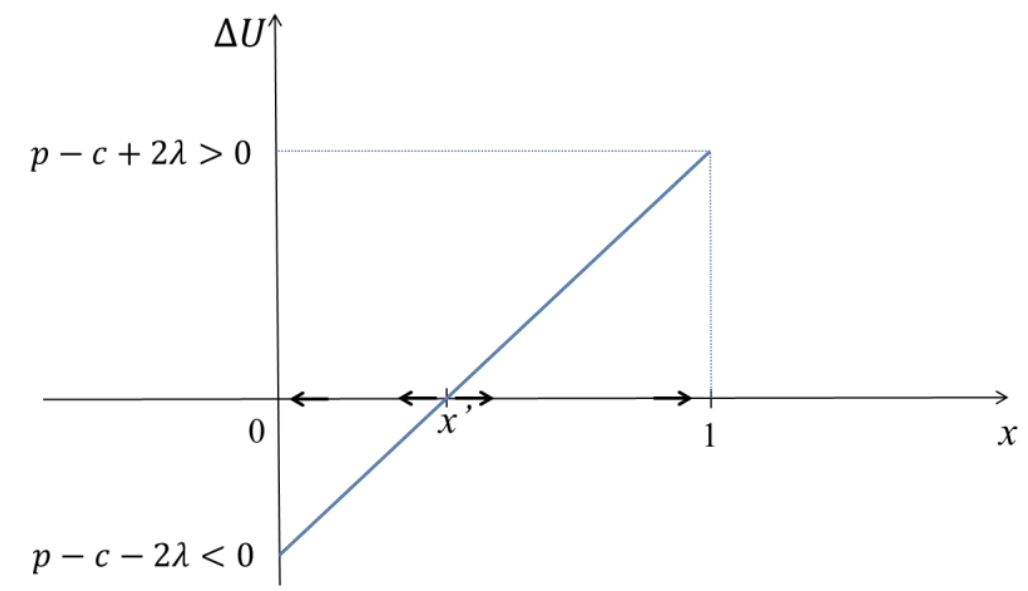

Fig. 3: Difference in farmer $i$ 's utility in the coordination game when $c+2 \lambda<p<c+2 \lambda$

This model illustrates that the descriptive norm can be an obstacle in the early phases of implementation of a PES program. In the conditions where the three equilibria are possible $(c-$ $2 \lambda<p<c+2 \lambda)$, unless participation reaches a minimum threshold ( $\left.x^{\prime}\right)$, the descriptive norm is an impeding factor for enrolment. Only when a minimum level of participation is reached $\left(x^{\prime}\right)$ does the descriptive norm reinforce farmers' enrolment rate.

\subsection{Injunctive norm only: $\lambda=0$ and $\sigma>0$}

Two features characterize the role played by injunctive norms in farmers' enrolment into PES. Firstly, although our model focuses on farmers, we assume that this injunctive norm comes from the whole society: farmers but also and mainly non-farmers. Injunctive norms are generally considered to be exerted by peers exclusively, however, a preliminary survey on PES adoption revealed that people who seem to have an influential opinion are not only neighbour farmers but also other members of the society such as spouses and farm advisors (Le Coent, 2016). Secondly, the injunctive norm is of course to enrol (i.e. to contribute to the public good), however we assume here that the injunctive norm is exerted more strongly when the level of the environmental public $\operatorname{good} \bar{e}$ is low. Therefore, when no farmer is enrolled in PES schemes, the level of the environmental public good is at its lowest level. This is usually when the society strongly urges 
farmers to change their practices and to enrol in PES. However, as the state of the environment improves, i.e. the provision of public good increases, the injunction to enrol in PES weakens since the marginal utility of the public good decreases. Unlike the forces of conformism (the descriptive norm) which lead farmers not to enrol when few farmers participate, the injunctive norm is a driving force for enrolment and is at its highest when few farmers participate. When PES uptake increases, the injunctive norm plays a lesser role. This model specification is original because the injunctive and the descriptive social norms are generally considered to be congruent since "what is approved is often what is typically done" (Cialdini et al. 1990). In our case, descriptive and injunctive norms pull in two opposite directions when adoption rate is low.

Assume that conforming to the injunctive norm yields the following utility $u_{I N}$, which takes the following specification:

$$
u_{I N}=\frac{2 e_{i}-1}{\bar{e}+1}=\frac{2 e_{i}-1}{x+1}
$$

This specification reflects the fact that farmers perceive a utility when they conform to the injunctive norm. However, that utility decreases as the enrolment rate $x$ increases because the intensity of the injunctive norm decreases when the environmental state improves. Symmetrically, farmers perceive a disutility when they do not conform to the injunctive norm (see section 2). This disutility is also decreasing as $x$ increases. Note that the injunctive norm depends on what others farmers do only because farmers' enrolment directly impacts the state of the environment, indeed in our model $\bar{e}=x$. In other words, a farmer who does not enrol in PES $\left(e_{i}=0\right)$ feels social disapproval which decreases as the environmental state improves, i.e. when the provision of public good increases thanks to a higher enrolment rate. Alternatively, a farmer who enrols $\left(e_{i}=1\right)$ feels social approval, but social approval decreases as the environmental state improves, i.e. when $x$ increases (Figure 4). 


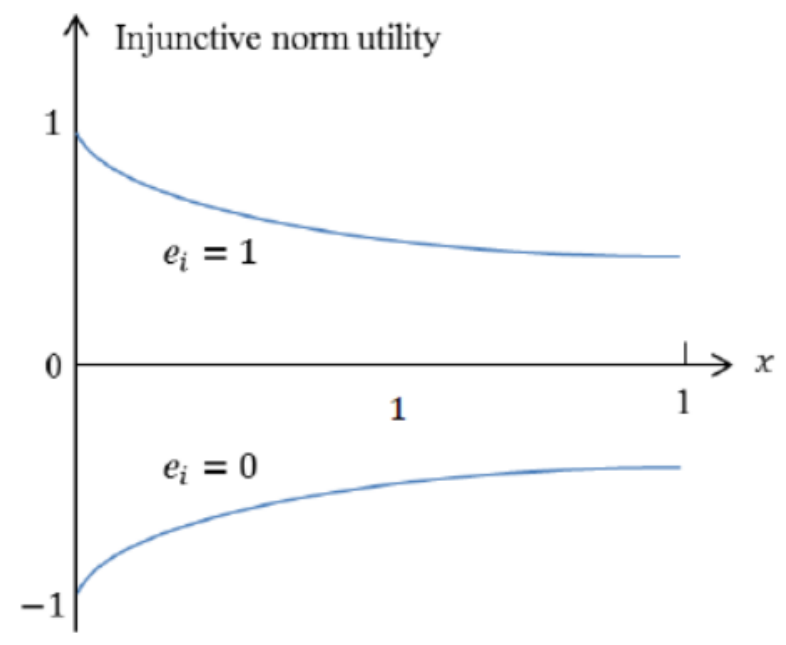

Fig. 4: Utility derived from the level of conformity with the injunctive norm

With this injunctive norm specification, farmer $i$ 's utility is:

$$
\begin{gathered}
U_{i}=(p-c) e_{i}+f(\bar{e})+\sigma \frac{2 e_{i}-1}{x+1} \\
\Delta U=p-c+\frac{2 \sigma}{x+1}
\end{gathered}
$$

with $\sigma$ the scale parameter for the injunctive norm reflecting the weight of the injunctive norm into the total utility or its salience.

Let $x^{\prime}$ be defined by $\Delta U=0$.

\section{Result 3:}

- The game has a Nash equilibrium in which every farmer enrols in PES if and only if $p>$ $c-\sigma$.

- The game has a Nash equilibrium in which no farmer enrols in PES if and only if $p \leq c-$ $2 \sigma$.

- The game has a Nash equilibrium in which a share $x^{\prime}$ offarmers enrol in PES if and only if $c-2 \sigma<p<c-\sigma$. 
Proof: As illustrated in Figure 5, note that $\Delta U$ is monotonously decreasing in $x$ on $[0,1]$. Thus, $e_{i}=1$ for all $i$ is a Nash equilibrium if and only if $\Delta U>0$ when $x=1$, i.e. if and only if $p>c-$ $\sigma$. Then, $e_{i}=0$ for all $i$ is a Nash equilibrium if and only if $\Delta U \leq 0$ when $x=0$, i.e. if and only if $p \leq c-2 \sigma$. Finally, $e_{i}=1$ for a share $x^{\prime}=-\frac{2 \sigma}{p-c}-1$ of farmers enrol in PES if and only if $c-2 \sigma<p<c-\sigma$. Note that if $p=c-2 \sigma$ then $x^{\prime}=0$ and the equilibrium $e=x^{\prime}$ corresponds to the polar Nash equilibrium $e=0$ because if $x=0$, in that case $\Delta U=0$ and nobody enrols. However, if $p=c-\sigma$ then $x^{\prime}=1$, thus $\Delta U=0$ and in that case everybody prefers not to enrol, therefore $e=1$ is not a Nash equilibrium, nor $e=0$ since $\Delta U>0$ when $x=0$. The lack of Nash equilibrium when $p=c-\sigma$ just comes from the fact that we assume that the farmers enrol in PES only if their utility strictly increases $(\Delta U>0)$.

The three types of Nash equilibria in relation to the value of $p$ are presented in Figure 6.

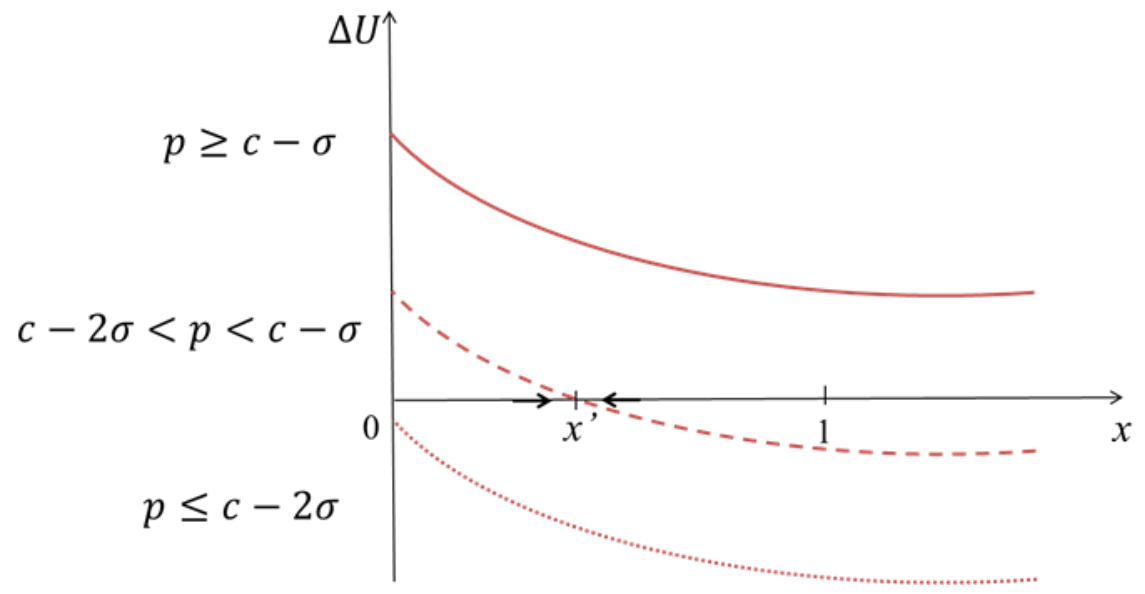

Fig. 5: Difference in farmer $i$ 's utility in the three cases according to the value of $p$ compared to $c-2 \sigma$ and $c-\sigma$ 


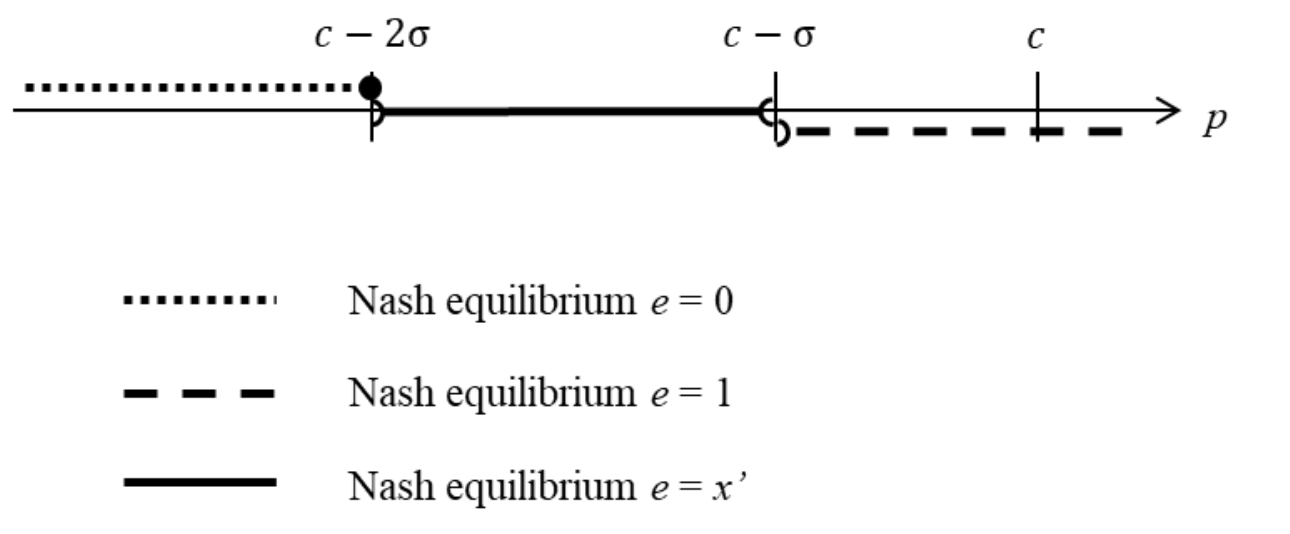

Fig. 6: Nash equilibria with the injunctive norm in relation with the value of $p$

Corollary: As defined here, the injunctive norm shall only have a positive impact on enrolment. $p<c$ is no longer a sufficient condition for farmers not to enrol in PES as the injunctive norm effect (social approval vs social disapproval) may compensate a payment which might be lower than the cost of enrolment.

Contrary to Result 2 with descriptive norm only, Result 3 shows that, with injunctive norm only, the game is not a coordination game. Indeed, the necessary and sufficient conditions for each type of Nash equilibrium do not overlap with each other (Figure 6). Thus, we do not need to refer to an evolutionary analysis to confirm that this game, with injunctive norm alone, has a unique Nash equilibrium (except when $p=c-\sigma$, no equilibrium) which is an asymptotically stable state. The nature of that equilibrium depends on the relative value of the parameters and we can have $e=0$, $e=1$ or $e=x^{\prime}$

\subsection{Combining descriptive and injunctive norms: $\lambda>0$ and $\sigma>0$}

Combining descriptive and injunctive norms with previous specification in farmer $i$ 's utility gives:

$$
U_{i}=(p-c) e_{i}+\beta \bar{e}+\lambda\left(2 e_{i}-1\right)(2 x-1)+\sigma \frac{2 e_{i}-1}{x+1}
$$




$$
\Delta U=p-c+2 \lambda(2 x-1)+\frac{2 \sigma}{x+1}
$$

$\frac{d \Delta U}{d x}=0$ if $x=\hat{x}=\sqrt{\frac{\sigma}{2 \lambda}}-1$.

$\Delta U$ is decreasing if and only if $x<\hat{x}$ and $\Delta U$ is increasing if and only if $x>\hat{x}$.

The value of $\Delta U$ is minimum when $x=\hat{x}$.

This more complex specification leads to different cases depending whether:

- $\hat{x} \leq 0$ (case 1 ), if and only if $\sigma \leq 2 \lambda$ (case 1 )

- $0<\hat{x}<1$ (case 2) if and only if $2 \lambda<\sigma<8 \lambda$ (case 2)

- $\hat{x} \geq 1$ (case 3) if and only if $\sigma \geq 8 \lambda$ (case 3)

Falling into one case or another therefore only depends on the relative weight that farmers grant to the descriptive norm $(\lambda)$ and the injunctive norm $(\sigma)$ i.e. the relative strengths of the descriptive and the injunctive norms. In case 1, the descriptive norm outweighs the injunctive norm, and we have similar results to those presented in section 2.2 (descriptive norm only). Symmetrically, case 3 is similar to what happens in section 2.3 (injunctive norm only).

Cases 1 and 3 have three subcases each. These subcases depend on the sign of $\Delta U$ when $x \in[0,1]$. This determines the number and the types of equilibria (see SI - Appendix B for a description of each subcase).

One interesting case is case 2 in which $\lambda$ and $\sigma$ are relatively similar. It has five subcases. The subcase $2 b$ ) is particularly challenging because it presents three Nash equilibria: two in which only a share of the population enrols in the PES ( $x^{\prime}$ and $\left.x^{\prime \prime}\right)$ and one in which everybody enrols. There are however only two asymptotically stable states in this coordination game: $e=x^{\prime}$ and $e=1$ This case is presented in Figure 7. 


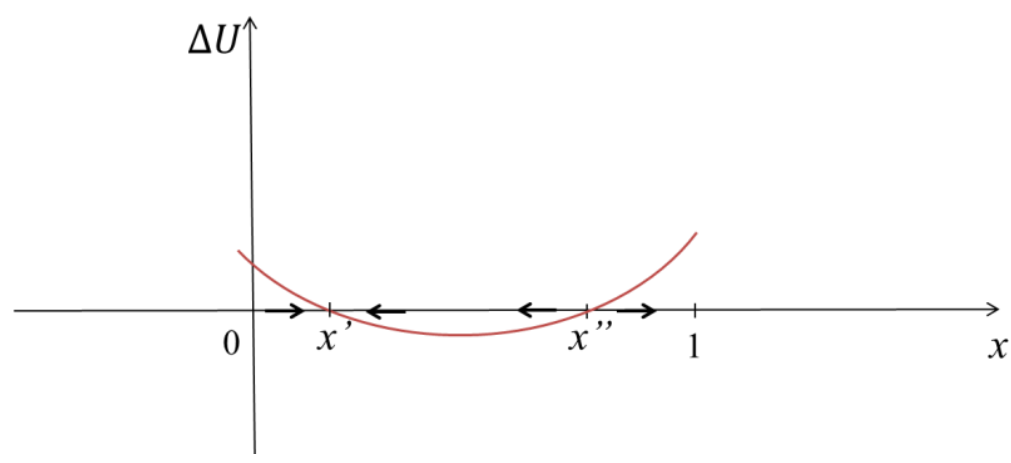

Fig. 7: Utility variation for subcase $2 b$ )

A first level of participation $x^{\prime}$ can be attained, mainly thanks to the effect of the injunctive norm. However, beyond that point, only if the participation rate reaches a level superior to $x^{\prime \prime}$ can the descriptive norm guarantee a significant improvement in enrolment, up to full participation.

This subcase could describe the situation observed in many areas where PES have been introduced and their adoption rates have remained limited. Thanks to contract payments and under the effect of injunctive norms, the first equilibrium may be attained. However, the descriptive norm influences adoption negatively, and does not allow to improve participation into PES significantly.

Our model provides insights on the isolated and combined effects of the descriptive and injunctive social norms on the adoption of PES. The model reveals that different situations are possible depending on the relative weight or salience of the norms: $\lambda$ and $\sigma$.

\section{Discussion and policy recommendations}

\subsection{Model's limits and empirical considerations}

The theoretical model presented above focuses exclusively on social norms, leaving aside other factors explaining farmers' decisions to enrol into PES schemes. In our framework, farmers' 
imitation behaviours are induced by the weight of the descriptive norm. Of course, there are also other factors explaining why farmers tend to behave in the same way as the majority of their peers. These reasons are notably linked to interdependencies and spill-over effects in the production process (see e.g. Lewis et al., 2011). For example, when a significant share of fellow farmers in the same neighbourhood adopt similar technologies, their costs and risks are potentially reduced because they benefit from shared experience and mutual learning, collective and coordinated actions and (sometimes) economies of scale in adoption costs. Within this perspective, public policies have paid increasing attention to incentives targeting the collective enrolment of farmers in agri-environmental schemes, such as financing group advisory services, or collective purchase of shared equipment. Yet, we argue that policy measures also have to take into account the impact of the descriptive norm per se, especially when the starting situation is one of low enrolment.

The intensity of the injunctive norm depends on the extent to which the environmental issues at stake are perceived as the sole responsibility of farmers' actions. Local public bads, like air pollution due to pesticide spraying on vineyards near inhabited area, or bad drinking water quality due to excess nitrogen fertilization, are emblematic situations when the injunctive norm exerted by the neighbourhood on farmers can be strong. The injunctive norm on farmers to preserve biodiversity or mitigate climate change exists as well, but is weaker, because society usually understands that the farming sector can only contribute partially to the solution and cannot be deemed fully responsible for the situation. The salience of the injunctive norm is therefore dependent on the type of environmental benefits targeted by PES schemes.

Identifying the relative weight of the descriptive and injunctive norm in farmers' decisions to participate in PES schemes in different contexts remains an empirical question. Several approaches could be used to estimate these weights, notably experimental approaches. Field experiments are increasingly used to estimate the influence of different behavioural factors on human decisions and to help include behavioural considerations in policy design (Allcott, 2011; Ferraro et al., 2011; 
Schultz, 1999; Cialdini et al., 1990; Shang and Croson, 2009, Thoyer and Préget, 2019). These approaches have the advantage of estimating a robust causality link between the behavioural factor and the studied outcome. However, they usually estimate the different behavioural factors in isolation and require the introduction of an exogenous variation of the norm to estimate the impact on the studied behaviour, which is particularly difficult in this context. Designing a protocol to build treated groups and a control group among farmers in order to measure the impact of a norm would indeed be an experimental challenge. Another approach is to use lab-in-the field experiments with farmers to estimate the relative weights of injunctive and descriptive norms. Although this approach may have a high internal validity, it is uncertain whether the values of $\lambda$ and $\sigma$ determined with such decontextualized experiments may actually apply to farmers' decisions to participate in PES schemes. Finally, social psychology has developed methods based on surveys, such as the Theory of Planned Behavior (Ajzen, 1991), to estimate the influence of personal and social motivations in the decision to adopt pro-environmental behaviour but estimations are often plagued by weak econometric identification strategies.

Despite the difficulty identifying empirically the weight of social norms in farmers' utility functions, our model could be useful to enrich agent-based models. Although our model is static, the evolutionary game theoretic approach used to solve our model introduces dynamic aspects. Agent-based models are frequently used in agricultural applications to address dynamic problems and agent interdependencies (see e.g. Huber et al. 2018), thus it would be interesting to compare our results with outcomes from simulations conducted with an agent-based model in which farmers' utility would include social norm components as proposed in our model.

\subsection{Policy recommendations}

A number of policy recommendations can be drawn from our theoretical approach. Firstly, moving from low participation equilibrium may be obtained by playing on the levels of net payments $p-$ 
$c$. The use of a dynamic payment system may be particularly relevant. For example, the regulator could offer a high payment rate at the start of the programme, to boost enrolment and to bring the overall participation rate beyond the high equilibrium point. Once this threshold participation level is reached, he can then reduce the payment for new entrants since the strength of the descriptive norm combined with the injunctive norm will henceforth be sufficient to ensure full participation. This two-tier payment can be efficient whilst at the same time limit budget expenditures.

Another policy option is to influence the relative values of $\lambda$ and $\sigma$. Indeed, although both norms may influence behaviour, they are not in force at all times and in all situations. Norms need to be "activated" in order to have an effect and this requires the norm to be made salient, i.e. attention needs to be focused on this particular norm (Cialdini et al., 1990). Parameters $\lambda$ and $\sigma$ also capture the salience and visibility of social norms. The more salient a social norm, the greater its weight in the utility function. If a communication campaign promotes the necessity to reduce the use of pesticides because of their impact on nature and health, it may contribute to reinforce the scope of the injunctive norm and therefore the value of $\sigma$ relative to $\lambda$, thus increasing the chances to land on a stable high (or full) participation equilibrium. Reinforcing the descriptive norm can also be effective when adoption rates are already high, or when they are low, by signalling that higher participation rates could be reached. Using the lever of the descriptive norm can also be effective, notably by strengthening communication on the adoption rate of other farmers and/or the opinion of other farmers during the period when farmers have to decide to sign or not. The experiment carried out by Kuhfuss et al. (2016) shows the positive impact of revealing information on other farmers' decision on the maintenance of pro-environmental practices at the end of a PES contract, when the adoption rates communicated are high enough. Our model however shows that revealing this information may be counterproductive when adoption rates are low, because the descriptive norm actually limits adoption in this context. The use of communication campaigns (Benabou and Tirole, 2012; Nyborg et al., 2006) must thus be considered with care. In some cases, the effective policy is to target norm misperceptions. "Lifting the veil" (Bicchieri, 2006), i.e. modifying the 
perception of the norm, is indeed much easier than modifying the norm itself. The campaign aiming at educating students on the drinking behaviour of their peers in order to provide a clearer picture of the perceived drinking norm is a good example of a successful action to correct misperceptions on what others do and feel (Schroeder and Prentice, 1998). The credibility of social norm communication campaigns can, however, be eroded when people feel that information disclosed by the campaign is being manipulated or strategically selected. The ensuing ethical and trust issues may have an effect contrary to expected results (Asheim, 2010). Examples of failure of social norm campaigns which misreported data or used data considered unreliable by the target population are mentioned in Berkowitz (2004).

Another type of proposed intervention is to modify the payment rules in a way that changes beliefs about others' behaviours and thus the perceived descriptive norm. Conditioning the payment of PES schemes to a minimum level of farmers' participation can indeed increase participation by introducing new beliefs on the expected behaviour of other farmers. This was shown in a laboratory experiment with students (Le Coent et al., 2014). Kuhfuss et al. (2016) demonstrated with a discrete choice experiment conducted with French winegrowers that a greater enrolment rate in herbicide reduction measures can be obtained for lower payments, by conditioning only a portion of the payment to a threshold of collective participation.

\section{Conclusion}

This paper proposes a theoretical model of the influence of social norms on farmers' enrolment into PES schemes. Our model analyses the interplay between two types of social norms, which sometimes play in opposite directions. Whereas the injunctive norm tends to push the PES enrolment rate upwards, but with decreasing marginal efficiency, descriptive norms can have a counteracting effect, when the proportion of enrolled farmers is low. Thus, the expectation that social norms activation fosters pro-environmental behaviour and therefore yields greater levels of 
public good provision for lower economic incentives (the so-called multiplier effect of social norms) is not always verified.

Indeed, we show that the relative weights of injunctive and descriptive norms in farmers' preferences can induce different types of collective behaviour. When the weight of the descriptive norm $\lambda$ is large relative to the weight of the injunctive norm $\sigma$, the two stable Nash equilibria are either no participation or full participation. When the weight of the descriptive norm $\lambda$ is smaller relative to the weight of the injunctive norm $\sigma$, we identify cases in which the population might be trapped in a stable low participation equilibrium. With these model's findings, we propose policy recommendations to avoid this trap.

Although they are presented in the context of farming and agricultural policies, the findings of this paper could be extended to the more general setting of the impact of social norms on voluntary contributions to a public good. For example, the adoption of pro-environmental consumption choices is also guided in part by social norms. Society can remain trapped in low purchase rates for "green products" due to the combination of a weak injunctive norm and a descriptive norm showing a low proportion of green consumers. The dynamics of pro-social behaviours, such as wearing a mask or getting vaccinated in times of acute health crisis, or charity giving, can also be better understood by considering the simultaneous, and sometimes contradictory forces of descriptive and injunctive social norms. 


\section{Appendix A}

Following Rege (2014), we use the replicator dynamics to represent a "virtual" learning process of trial-and error.

"The replicator dynamics say that the growth rate of the population share using a certain strategy equals the difference between the strategy's current payoff and the current average payoff in the population (Weibull, 1995, p. 73).”

In our case, the replicator dynamics is given by:

$$
\dot{x}(x)=x\left(U_{i}^{1}(x)-\bar{U}(x)\right)
$$

Where $\bar{U}(x)=x U_{i}^{1}(x)+(1-x) U_{i}^{0}(x)$

$$
\begin{aligned}
& \dot{x}(x)=x(1-x) \Delta U(x) \\
& \dot{x}(x)=x(1-x)[p-c+2 \lambda(2 x-1)]
\end{aligned}
$$

Stationary states are determined by $\dot{x}(x)=0$. Thus, there are three stationary states: $x=0, x=1$ and $x=x^{\prime}=\frac{1}{2}-\frac{p-c}{4 \lambda}$.

For $0<x<1, \dot{x}>0$ if $\Delta U=p-c+2 \lambda(2 x-1)>0$ and thus if and only if $x>\frac{1}{2}-\frac{p-c}{4 \lambda}=x^{\prime}$. Symmetrically, for $0<x<1, \dot{x}<0$ if $\Delta U=p-c+2 \lambda(2 x-1)<0$ and thus if and only if $x<\frac{1}{2}-\frac{p-c}{4 \lambda}=x^{\prime}$. Hence, $x=x^{\prime}$ is not an asymptotically stable state because if the share of farmers who enrol in PES moves above $\max \left\{0, x^{\prime}\right\}$, then $x>x^{\prime}$ and $\Delta U>0$. Therefore, more farmers will enrol in PES. This process will continue until all farmers are enrolled and the asymptotically stable state $x=1$ is reached. Symmetrically, if the share of farmers who enrol in PES moves below $\min \left\{1, x^{\prime}\right\}$, then more farmers will quit the PES. This process will continue until all farmers leave the PES and the asymptotically stable state $x=0$ is reached. 


\section{Appendix B}

Case 1: $\hat{x} \leq 0 \Leftrightarrow \sigma \leq 2 \lambda$

The weight of the injunctive norm is not too strong relatively to the weight of the descriptive norm. In this first case $\Delta U$ is always increasing on $x \in[0,1]$ and there are 3 subcases shown on Figure B1.

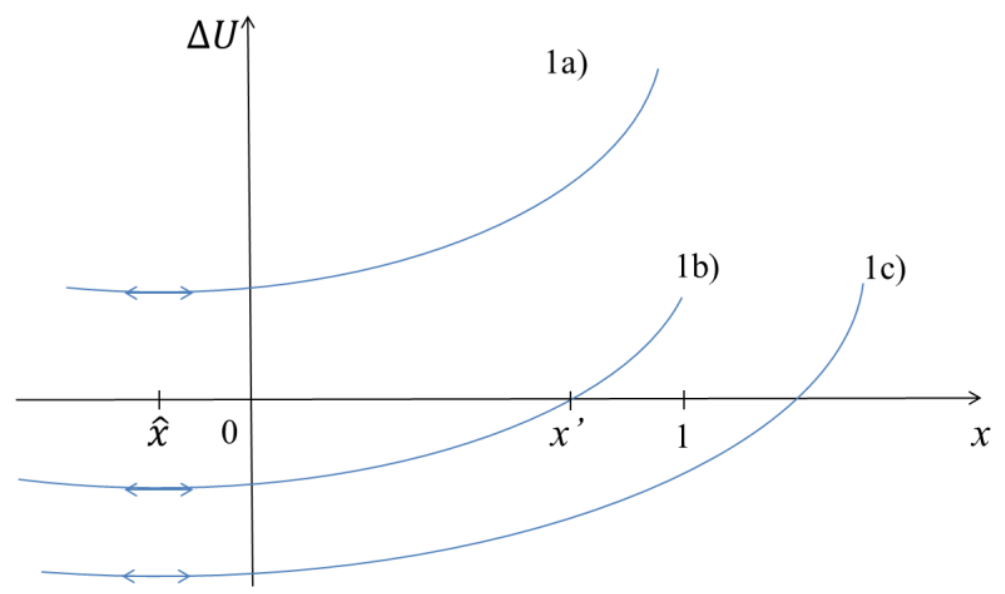

Fig. B1. Farmer's utility variation for cases 1

1a) If $\Delta U>0$ when $x=0$ then $\Delta U>0 \forall x \in[0,1]$. Thus there is a unique Nash equilibrium in which all farmers enrol in PES $(x=1)$.

1b) If $\Delta U<0$ when $x=0$ and $\Delta U>0$ when $x=1$ then there is a unique $x^{\prime} \in[0,1]$ such that $\Delta U\left(x^{\prime}\right)=0$. In that case there are three Nash equilibria: $x=0, x=1$ and $x=x^{\prime}$. However there are only two asymptotically stable states $x=0$ and $x=1$.

1c) If $\Delta U<0$ when $x=1$ then $\Delta U<0 \forall x \in[0,1]$ thus there is a unique Nash equilibrium in which no farmer enrols in PES $(x=0)$.

Case 2: $0<\hat{x}<1 \Leftrightarrow 2 \lambda<\sigma<8 \lambda$ 
The weight of the injunctive norm is not too strong and not too weak relatively to the weight of the descriptive norm. In this second case, $\Delta U$ is first decreasing until $\hat{x}$ and then increasing. There are 5 subcases, shown on Figure B2.

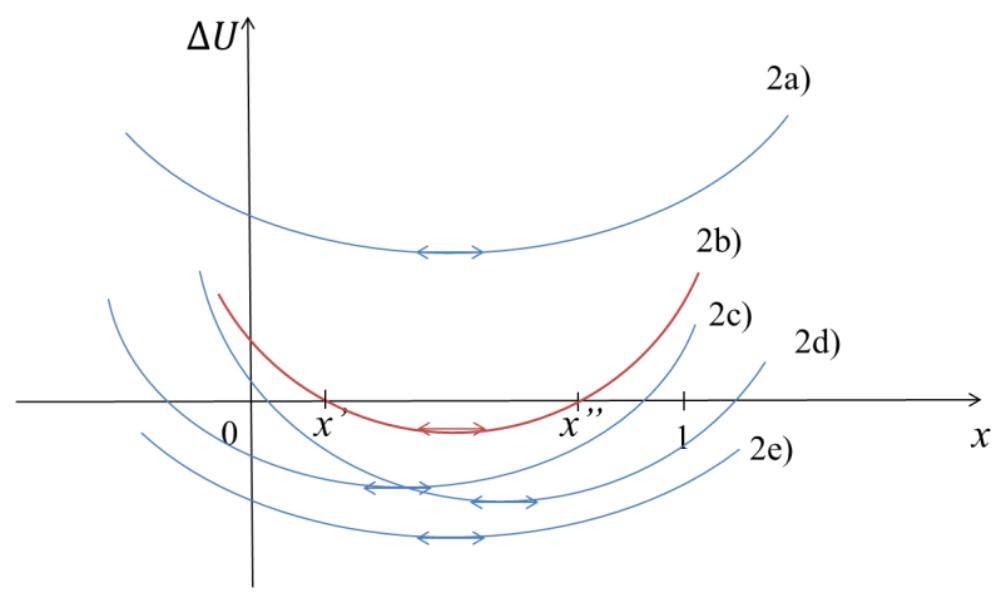

Fig. B2. Farmer's utility variation for cases 2

2a) If $\Delta U_{\min }>0$ then $\Delta U>0 \forall x \in[0,1]$ thus there is a unique Nash equilibrium in which all farmers enrol in PES $(x=1)$.

2b) If $\Delta U_{\min } \leq 0$ and $\Delta U>0$ when $x=0$ and $\Delta U>0$ when $x=1$ then there are two $x \in$ $[0,1]\left(x^{\prime}\right.$ and $\left.x^{\prime \prime}\right)$ such that $\Delta U\left(x^{\prime}\right)=\Delta U\left(x^{\prime \prime}\right)=0$. In that case, there are three Nash equilibria: $x=x^{\prime}, x=x^{\prime \prime}$ and $x=1$. However there are only two asymptotically stable states in this coordination game: $x=x^{\prime}$ and $x=1$.

2c) If $\Delta U_{\min } \leq 0$ and $\Delta U<0$ when $x=0$ and $\Delta U>0$ when $x=1$ then there is a unique $x^{\prime} \in$ $[0,1]$ such that $\Delta U\left(x^{\prime}\right)=0$. In that case there are three Nash equilibria: $x=0, x=1$ and $x=x^{\prime}$. However there are only two asymptotically stable states $x=0$ and $x=1$.

2d) If $\Delta U_{\min } \leq 0$ and $\Delta U>0$ when $x=0$ and $\Delta U<0$ when $x=1$ then there is a unique $x^{\prime} \in$ $[0,1]$ such that $\Delta U\left(x^{\prime}\right)=0$. In that case there is a unique Nash equilibria: $x=x^{\prime}$. 
2e) If $\Delta U_{\min } \leq 0$ and $\Delta U<0$ when $x=0$ and $\Delta U<0$ when $x=1$ then $\Delta U<0 \forall x \in[0,1]$ thus there is a unique Nash equilibrium in which no farmer enrols in PES $(x=0)$.

Case 3: $\hat{x} \geq 1 \Leftrightarrow \sigma \geq 8 \lambda$

The weight of the injunctive norm is strong relatively to the weight of the descriptive norm. In this last case $\Delta U$ is always decreasing and there are 3 subcases shown on Figure B3.

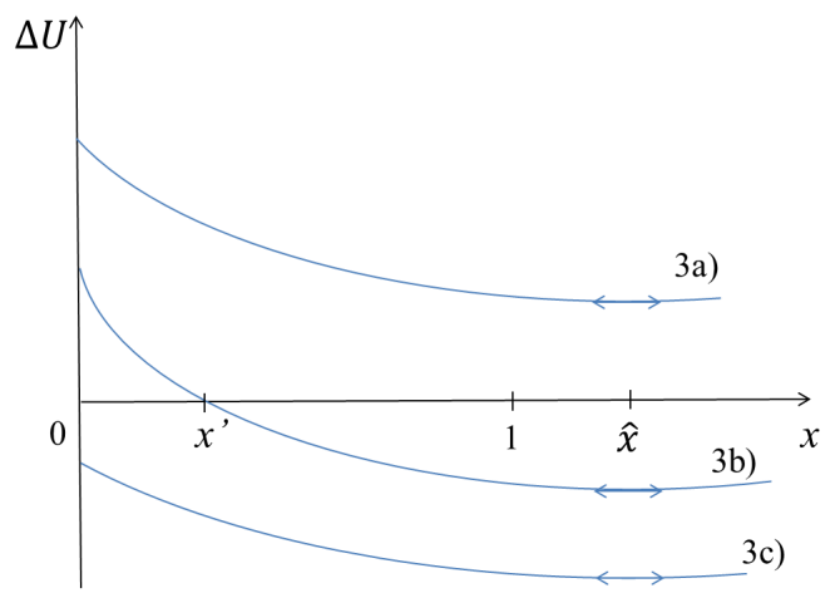

Fig. B3. Farmer's utility variation for cases 3

3a) If $\Delta U>0$ when $x=1$ then $\Delta U>0 \forall x \in[0,1]$ thus there is a unique Nash equilibrium in which all farmers enrol in PES $(x=1)$.

3b) If $\Delta U>0$ when $x=0$ and $\Delta U<0$ when $x=1$ then there is a unique $x^{\prime} \in[0,1]$ such that $\Delta U\left(x^{\prime}\right)=0$. In that case there is a unique Nash equilibria: $x=x^{\prime}$.

3c) If $\Delta U<0$ when $x=0$ then $\Delta U<0 \forall x \in[0,1]$ thus there is a unique Nash equilibrium in which no farmer enrols in PES $(x=0)$. 


\section{References}

Abbott A, Nandeibam S, O’Shea L (2013) Recycling: Social norms and warm-glow revisited. Ecological Economics 90:10-18.

Ajzen I (1991) The theory of planned behavior. Organizational Behavior and Human Decision Processes 50:179-211.

Allaire G, Cahuzac E, Simioni M (2009) Contractualisation etdiffusionspatiale des mesures agroenvironnementales herbagères. Revue d'Etudes en Agriculture et Environnement 90:23-50.

Allcott H (2011) Social norms and energy conservation. Journal of Public Economics 95:10821095

Asheim, G.B. (2010): Strategic use of environmental information, Environmental and Resource Economics 46: 207-216

Aronson E, Wilson TD, Akert RM, Sommers S (2018) Social psychology, $9^{\text {th }}$ ed, Pearson, Global edition, 621

Beedell J, Rehman T (2000) Using social-psychology models to understand farmers' conservation behaviour, Journal of Rural Studies 16:117-127

Benabou R, Tirole J (2012) Laws and norms. IZA Discussion Paper 6290

Berkowitz AD (2004) The Social Norms Approach: Theory, Research, and Annotated Bibliography

Bicchieri C (2006) The grammar of society. The Nature and Dynamics of Social Norms: Cambridge University Press, New York, New York

Brekke, K.A., K. Nyborg (2010) Selfish Bakers, Caring Nurses? A Model of Work Motivation. Journal of Economic Behavior and Organization 75:377-394

Burton RJF (2004) Seeing Through the 'Good Farmer's' Eyes: Towards Developing an 
Understanding of the Social Symbolic Value of 'Productivist' Behaviour: Sociologia Ruralis $44: 195-215$

Burton R, Schwarz G (2013) Result-oriented agri-environmental schemes in Europe and their potential for promoting behavioural change, Land Use Policy 30:628-641

Chabe-Ferret S, Subervie J (2013) How much green for the buck? estimating additional and windfall effects of french agro-environmental schemes by did-matching, Journal of Environmental Economics and Management 65:12-27

Chen X, Lupi F, He G, Liu J (2009) Linking social norms to efficient conservation investment in payments for ecosystem services. Proceedings of the National Academy of Sciences of the United States of America 106:11812-7

Cialdini RB, Reno RR, Kallgren CA (1990) A focus theory of normative conduct: Recycling the concept of norms to reduce littering in public places. Journal of personality and Social Psychology 58:1015-1026

Cialdini R, Trost M (1998) Social influence: Social norms, conformity and compliance. The Handbook of Social Psychology 2:151-192

Crocker J, Major B, Steele C (1998) Social Stigma, in Gilbert D., Fiske ST and Lindzey G. (eds) The handbok of social psychology, $4^{\text {th }}$ ed, Mc Grew Hill:504-553

Czajkowski M, Hanley N, Nyborg K (2017) Social Norms, Morals and Self-interest as Determinants of Pro-environment Behaviours: The Case of Household Recycling. Environmental and Resource Economics 66:647-670

Defrancesco E, Gatto P, Runge F, Trestini S (2008) Factors affecting farmers'participation in agrienvironmental measures: A northern Italian perspective. Journal of Agricultural Economics 59:114-131

Dessart FJ, Barreiro-Hurlé J, Van Bavel R (2019) Behavioural factors affecting the adoption of 
sustainable farming practices: a policy-oriented review, European Review of Agricultural Economics 46(3):417-471

Elster J (1989) Social Norms and Economic Theory. The Journal of Economic Perspectives 3:99117

Espinosa-Goded M, Barreiro-Hurle J, Dupraz P (2013) Identifying additional barriers in the adoption of agri-environmental schemes: the role of fixed costs. Land Use Policy 31:526-535

European Court of Auditors (2011) Is agri-environment support well designed and managed? Special Report No 7, p 82

Farrow K, Grolleau G, Ibanez L (2017) Social Norms and Pro-environmental Behavior: A Review of the Evidence. Ecological Econnmics 140:1-13

Ferraro PJ, Miranda JJ, Price MK (2011) The persistence of treatment effects with norm-based policy instruments: Evidence from a randomized environmental policy experiment. American Economic Review 101:318-322

Huber, R., Bakker, M., Balmann, A., Berger, T., Bithell, M., Brown, C., Grêt-Regamey, A., Xiong, H., Le, Q.B., Mack, G., Meyfroidt, P., Millington, J., Müller, B., Polhill, J.G., Sun, Z., Seidl, R., Troost, C., Finger, R. (2018). Representation of decision-making in European agricultural agent-based models. Agricultural Systems 167: 143-160

Kuhfuss L, Preget R, Thoyer S (2014) Préférences individuelles et incitations collectives : quels contrats agroenvironnementaux pour la réduction des herbicides par les viticulteurs? Revue d'Études en Agriculture et Environnement 95:111-143

Kuhfuss L, Préget R, Thoyer S, Hanley N, Le Coent P, Désolé M (2016) Nudges, social norms and permanence in agri-environmental schemes. Land Economics 92:641-655

Lähdesmäki M, Siltaoja M, Luomala H, Puska P and Kurki S (2019) Empowered by stigma? Pioneer organic farmers' stigma management strategies. Journal of Rural Studies 65:152-160 
Le Coent P, Préget R, Thoyer S (2014) Why pay for nothing? An experiment on a conditional subsidy scheme in a threshold public good game. Economics Bulletin 34:1976-1989

Le Coent P (2016) Agri-environmental schemes: behavioral insights and innovative designs, Unpublished $\mathrm{PhD}$ thesis, University of Montpellier

Lewis, David J., Bradford L. Barham, and Brian Robinson. 2011. “Are There Spillovers in the Adoption of Clean Technology? The Case of Organic Dairy Farming.” Land Economics 87 (2): $250-67$.

Lindbeck A, Nyberg S, Weibull JW (1999) Social norms and economic incentive in the welfare State, Quarterly Journal of Economics 114:1-35

Lopes A., Viriyavipart A. and Tasneem D. (2020) The role of social influence in crop residue management: evidence from Northern India, Ecological Economics 169 DOI: 106563

Mamine F, Fares M, Minviel JJ (2020) Contract design for adoption of agri-environmental practices: a meta-analysis of discrete choice experiments. Ecological Economics 176 DOI: 106721

Mettepenningen E, Vandermeulen V, Delaet K, Van Huylenbroeck G, Wailes E (2013) Investigating the influence of the institutional organisation of agri-environmental schemes on scheme adoption, Land Use Policy 33:20-30

Mills J, Gaskell P, Ingram J, Chaplin S (2018) Understanding farmers' motivations for provinding unsubsidised environmental benefits, Land Use Policy 76:697-707

Nyborg K, Howarth RB, Brekke KA (2006) Green consumers and public policy: On socially contingent moral motivation. Resource and Energy Economics 28:351-366

Nyborg K (2018) Social Norms and the Environment. Annual Review of Resource Economics $10: 405-423$

OECD - Trade and agriculture Directorate- Environment Directorate (2019) Economic and 
environmental sustainability performance of environmental policies in agriculture: a literature review, COM/TAD/CA/ENV/EPOC(2029)2/FINAL, p 62

Pannell DJ, Claasen R (2020) The roles of adoption and behaviour change in agricultural policy, Applied Economic Perspectives and Policy 42:31-41

Rege M (2004) Social Norms and Private Provision of Public Goods. Journal of Public Economic Theory 6:65-77

Schroeder CM, Prentice D (1998) Exposing Pluralistic Ignorance to Reduce Alcohol Use Among College Students. Journal of Applied Social Psychology 28:2150-2180

Schultz PW (1999) Changing Behavior With Normative Feedback Interventions: A Field Experiment on Curbside Recycling. Basic and Applied Social Psychology 21:25-36

Shang J, Croson R (2009) A field experiment in charitable contribution: The impact of social information on the voluntary provision of public goods. The Economic Journal 119:14221439

Thoyer, S., Préget, R. (2019). Enriching the CAP evaluation toolbox with experimental approaches: introduction to the special issue. European Review of Agricultural Economics 46(3): 347-366

Villamayor-Tomas S, Sagebiel J, Olschewski R (2019) Bringing the neighbors in: A choice experiment on the influence of coordination and social norms on farmers' willingness to accept agro-environmental schemes across Europe. Land Use Policy 84:200-215

Westerink J, Pérez-Soba M, van Doorn A (2020) Social learning and land lease to stimulate the delivery of ecosystem services in intensive arable farming. Ecosystem Services 44 DOI: 101149 